\title{
Redox-sensitive polymeric micelles with aggregation-induced emission for bioimaging and delivery of anticancer drugs
}

\author{
Changzhen Sun ${ }^{1,2+}$, Ji Lư ${ }^{1 \dagger}$, Jun Wang ${ }^{1}$, Ping Hao ${ }^{3}$, Chunhong Li ${ }^{1}$, Lu Qi ${ }^{1}$, Lin Yang ${ }^{1}$, Bin He ${ }^{4}$, Zhirong Zhong ${ }^{1 *}$ \\ and $\mathrm{Na} \mathrm{HaO}^{1 *}$ (1)
}

\begin{abstract}
Background: Nano-drug delivery systems show considerable promise for effective cancer therapy. Polymeric micelles have attracted extensive attention as practical nanocarriers for target drug delivery and controlled drug delivery system, however, the distribution of micelles and the release of the drug are difficult to trace in cancer cells. Therefore, the construction of a redox-sensitive multifunctional drug delivery system for intelligent release of anticancer drugs and simultaneous diagnostic imaging and therapy remains an attractive research subject.

Results: To construct a smart drug delivery system for simultaneous imaging and cancer chemotherapy, mPEGss-Tripp was prepared and self-assembled into redox-sensitive polymeric micelles with a diameter of $105 \mathrm{~nm}$ that were easily detected within cells using confocal laser scanning microscopy based on aggregation-induced emission. Doxorubicin-loaded micelles rapidly released the drug intracellularly when GSH reduced the disulfide bond. The drug-loaded micelles inhibited tumor xenografts in mice, while this efficacy was lower without the GSH-responsive disulfide bridge. These results establish an innovative multi-functional polymeric micelle for intracellular imaging and redox-triggered drug deliver to cancer cells.
\end{abstract}

Conclusions: A novel redox-sensitive drug delivery system with AIE property was constructed for simultaneous cellular imaging and intelligent drug delivery and release. This smart drug delivery system opens up new possibilities for multifunctional drug delivery systems.

Keywords: Polymeric micelles, Redox-sensitive, Aggregation-induced emission, Drug delivery, Bioimaging

\section{Background}

Nanocarriers have attracted extensive attention as practical methods for target drug delivery and controlled drug delivery system for highly efficient anticancer therapy $[1,2]$. Among these carriers, polymeric micelles, selfassembling from amphiphilic block copolymers, are of great interest and importance, because of several merits

\footnotetext{
*Correspondence: zhongzhirong@126.com; haona@swmu.edu.cn

${ }^{\dagger}$ Changzhen Sun and Ji Lu contributed equally in this work

${ }^{1}$ Department of Pharmaceutical Sciences, School of Pharmacy, Southwest Medical University, Luzhou 646000, China

Full list of author information is available at the end of the article
}

such as the enhanced water solubility, improved biocompatibility, decreased side effects, passive accumulation of the drugs in the tumor tissues and prolonged circulating time. Although considerable efforts on developing efficient polymeric micelles have been made in recent years, especially, several polymeric micelles have been reached to clinical trials $[3,4]$, the distribution of micelles and the release of the drug is difficult to trace in cancer cells $[5,6]$. Therefore, the development of theranostic nanoparticles with integrated with diagnostic imaging and therapeutic capability is urgent needed for drug delivery systems [7-9]. However, the classical methodology that encapsulates traditional fluorescent dyes into the core of 
nanoparticles [10-12], often suffered from fluorescence quenching of fluorescence agents in an aggregated state because of the aggregation caused quenching (ACQ) effect, which greatly reduces the fluorescence intensity and impedes the imaging effect, limiting their biomedical applications [13-15]. In 2001, Tang developed a class of novel category of fluorophores with aggregation-induced emission (AIE) characteristics, which exhibit high emission efficiencies in an aggregated state [16, 17]. Recently, the relevant AIE probes have been employed for cell imaging [18-21]. This unique property makes the AIEactive polymeric micelles as the drug nanocarriers available for simultaneous cancer diagnostic and therapy.

When the drug-loaded micelles reaches the target tumor tissues, rapid release of the drug is required to improve antitumor efficacy and circumvent drug resistance in pathological cells. In this regard, smart polymeric micelles with stimuli-sensitive features have been explored for target site-triggered drugs release in response to appropriate environment of tumor tissues [22-26]. Among various stimuli-sensitive antitumor drug nanocarriers, redox-sensitive disulfide linkage contained polymeric micelles have attracted more and more attention for controlled delivery and intelligent release of anticancer drugs. Disulfide linkage of the polymeric micelles can be quickly cleaved by reductive substance glutathione (GSH) via thiol-disulfide exchange [27] at high concentration of GSH in the intracellular environment of tumor cells (approximately $2-10 \mathrm{mM}$ ), while relatively stable at a low concentration of GSH in the extracellular environment (approximately 2-20 $\mu \mathrm{M}$ ) [24, 28]. Moreover, the GSH concentration in tumor cells is typically at least four times higher than the values of healthy cells $[29,30]$. In this context, the construction of a redox-sensitive multifunctional drug delivery system taking advantage of this characteristic for intelligent release of anticancer drugs and simultaneous cancer diagnostic and therapy remains an attractive research subject.

In this study, a redox-sensitive drug delivery system with AIE property was constructed for simultaneous cellular imaging and intelligent drug delivery and release. We conjugated the AIE fluorophore Tripp to methoxy-PEG via a redox-sensitive disulfide bond. As a control, we also prepared redox-insensitive mPEGTripp. We anticipated that the synthetic polymer molecule would self-assemble into micelles in which mPEG would serve as a biocompatible shell that would circulate in the blood for a long time, and the hydrophobic AIE core would allow cellular imaging and loading of hydrophobic anticancer drug such as doxorubicin (DOX). The disulfide bridge, in turn, would help ensure rapid release of the drug within tumor cells but not in the circulation (Scheme 1).

\section{Materials and methods \\ Materials}

Methoxypoly (ethylene glycol) (mPEG; Mw 2000 g/ mol), succinic anhydride (SAA), chloroform-D $\left(\mathrm{CDCl}_{3}\right.$, 99.8\%) and deuterated dimethyl sulphoxide (DMSO- $d_{6}$ ) were purchased from Sigma-Aldrich (Shanghai, China); 1-ethyl-(3-dimethylaminopropyl)-carbodiimide hydrochloride (EDC. $\mathrm{HCl})$, methyl 4-aminobenzoate and 1-hydroxy-benzotriazole monohydrate (HOBt), from GL Biochem (Shanghai, China); tetramethylethylenediamine, $\mathrm{N}, \mathrm{N}$-diisopropyl ethylamine (DIEA) and 4-dimethylaminopyridine (DMAP), from Aladdin Chemistry (Shanghai, China); 1,3-dicyclohexylcarbodiimide (DCC) and cystamine dihydrochloride, from Asta Tech Biopharm (Chengdu, China); and doxorubicin hydrochloride (DOX $\cdot \mathrm{HCl}$ ), from Shanghai Yingxuan Chempharm (Shanghai, China). DOX was deprotonated as reported [31]. All solvents were obtained from Chengdu Kelong Chemical (Chengdu, China) and purified before use. Dulbecco's Modified Eagle's Medium (DMEM), Roswell Park Memorial Institute (RPMI) 1640 medium, fetal bovine serum (FBS), and the cell counting kit-8 (CCK-8) were purchased from Life Technologies (Gibco, USA).

\section{Synthesis of redox-sensitve amphiphiles mPEG-ss-Tripp Synthesis of MPEG-SAA}

The mPEG $(0.2 \mathrm{~g}, 0.1 \mathrm{mmol})$ and SAA $(0.05 \mathrm{~g}, 0.5 \mathrm{mmol})$ were dissolved in $60 \mathrm{~mL}$ of anhydrous $\mathrm{CH}_{2} \mathrm{Cl}_{2}$ with strong stirring. Pyridine $(0.4 \mathrm{~mL})$ was added dropwise to the mixture on an ice bath. The mixture was stirred at room temperature for $48 \mathrm{~h}$. An appropriate amount of acetic acid was added to the reaction system under stirring in order to neutralize salts produced in the system. The precipitate was removed by filtration, the filtrate was evaporated and the crude product was precipitated in a large volume of cold diethyl ether. This purification procedure was repeated several times to yield mPEG-SAA.

\section{Synthesis of mPEG-ss- $\mathrm{NH}_{2}$}

The mPEG-SAA $(0.81 \mathrm{~g}, 0.4 \mathrm{mmol}), \mathrm{EDC} \cdot \mathrm{HCl}(0.32 \mathrm{~g}$, $1.6 \mathrm{mmol})$ and HOBT $(0.22 \mathrm{~g}, 1.6 \mathrm{mmol})$ were dissolved in $60 \mathrm{~mL}$ of DMF and stirred at room temperature for $3 \mathrm{~h}$. To the solution was added cystamine dihydrochloride $(0.14 \mathrm{~g}, 0.6 \mathrm{mmol})$, and the mixture was vigorously stirred at room temperature for $48 \mathrm{~h}$. Then the mixture was filtered and concentrated under reduced pressure. The dark brown residual oil was redissolved in $\mathrm{CH}_{2} \mathrm{Cl}_{2}$, and the organic phase was extracted three times with a saturated aqueous solution of sodium chloride, dried with anhydrous $\mathrm{MgSO}_{4}$ overnight and concentrated. The crude product was precipitated three times in cold anhydrous diethyl ether and dried under vacuum to obtain light-yellow solid mPEG-ss- $\mathrm{NH}_{2}$. 


\section{Synthesis of $\mathrm{mPEG}$-ss-Tripp}

The mPEG-ss- $\mathrm{NH}_{2}(0.45 \mathrm{~g}, 0.2 \mathrm{mmol})$, Tripp-COOH [32] (0.21 g, $0.6 \mathrm{mmol}), \mathrm{EDC} \cdot \mathrm{HCl}(0.16 \mathrm{~g}, 0.8 \mathrm{mmol})$ and HOBT $(0.11 \mathrm{~g}, 0.8 \mathrm{mmol})$ were added to $60 \mathrm{~mL}$ of DMF, then DIEA $(0.2 \mathrm{~mL}, 1.2 \mathrm{mmol})$ was injected into the solution, and the mixture was stirred at room temperature for $48 \mathrm{~h}$. The solvent was evaporated under reduced pressure, and the residue was dissolved in $\mathrm{CH}_{2} \mathrm{Cl}_{2}$. The organic phase was washed three times with a saturated aqueous solution of sodium chloride and dried over anhydrous $\mathrm{MgSO}_{4}$. The filtrate was concentrated and precipitated twice in cold diethyl ether to yield mPEG-ss-Tripp.

\section{Characterization}

Products were analyzed in DMSO- $d_{6}$ using ${ }^{1} \mathrm{H}$ NMR (Ascend $400 \mathrm{MHz}$, Bruker), with tetramethylsilane as an internal reference. Micelle size and size distribution were analyzed by dynamic light scattering (Malvern ZetasizerNano ZS, UK). Micelle morphology was observed using scanning electron microscopy (S4800, Hitachi,
Japan). Samples were prepared for electron microscopy by dipping a silicon pellet into a solution of freshly prepared micelles, then drying the pellet overnight at room temperature.

\section{Preparation of drug-loaded micelles}

Drug-loaded micelles DOX/mPEG-ss-Tripp were prepared using a dialysis method. Briefly, freeze-dried amphiphilic mPEG-ss-Tripp (10 mg) and DOX $(2.5 \mathrm{mg})$ were co-dissolved in $1 \mathrm{~mL}$ of DMSO, dispersed slowly into $10 \mathrm{~mL}$ of deionized water and stirred vigorously overnight. Then, the mixtures were dialyzed against deionized water at $4{ }^{\circ} \mathrm{C}$ for $12 \mathrm{~h}$ in dialysis tubing (Spectra/Por) with a molecular weight cut-off of $1 \mathrm{kDa}$. The solution was removed from the dialysis tubing, centrifuged and freeze-dried. Redox-insensitive DOX/mPEGTripp micelles were prepared in the same way.

DOX content of drug-loaded micelles was determined by UV/vis spectroscopy (Specord 200 PLUS, Germany) at $480 \mathrm{~nm}$ using a standard calibration curve obtained from

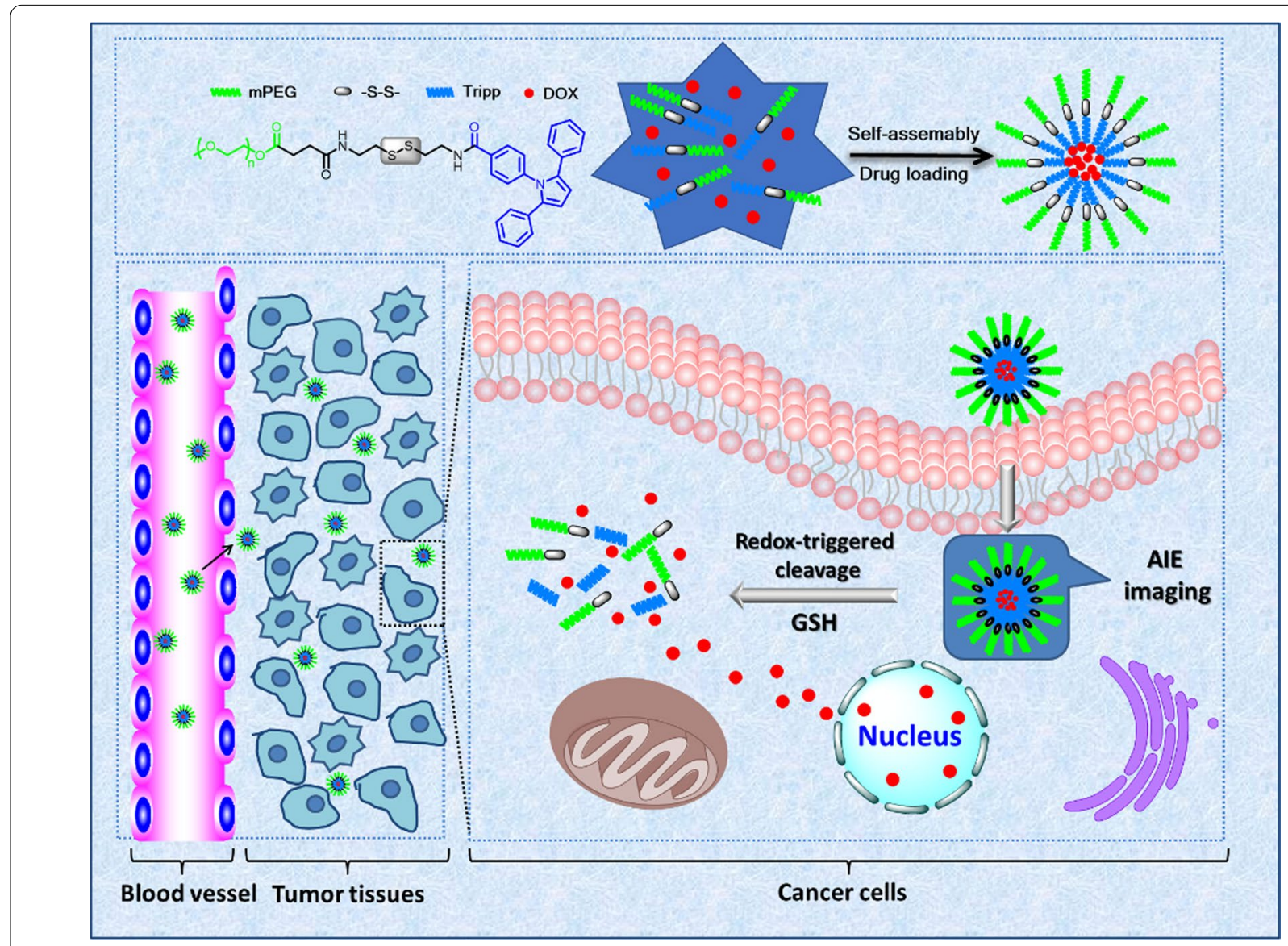

Scheme 1 The schematic representation of redox-sensitive copolymers polymeric micelles with AIE imaging for cancer therapy 
solutions containing different concentrations of DOX in DMSO. Solutions were shielded from light. Drug loading content (DLC) and encapsulation efficiency (DLE) were calculated according to the following formulas:

\section{Cellular uptake of micelles}

Uptake of micelles by $4 \mathrm{~T} 1$ cells was analyzed using confocal laser scanning microscopy and flow cytometry. Cells in logarithmic growth were seeded in $35-\mathrm{mm}$

DLC $(\%)=($ weight of loaded DOX/weight of drug - loaded micelle $) \times 100 \%$

DLE $(\%)=$ (weight of loaded DOX/weight of drug in feeding) $\times 100 \%$

\section{In vitro drug release}

Profiles of DOX release from micelles were investigated in phosphate-buffered saline (PBS; pH 7.4 and $\mathrm{pH} 5.5$, ionic strength $=0.01 \mathrm{M}$ ) alone or supplemented with $10 \mathrm{mM} \mathrm{GSH}$. Briefly, $1 \mathrm{~mL}$ of drug-loaded micelles were transferred into dialysis tubes (Spectra/ Por) with a molecular weight cut-off of $1 \mathrm{kDa}$ and immersed in $25 \mathrm{~mL}$ of release medium in vials with continuous shaking at $120 \mathrm{rpm}$ and $37^{\circ} \mathrm{C}$. At predetermined intervals, $1 \mathrm{~mL}$ of release medium was taken out and replaced with an equal volume of fresh medium. The released DOX was detected using a fluorescence spectrometer (F-7000, Hitachi, Japan) with excitation at $480 \mathrm{~nm}$ and emission at $550 \mathrm{~nm}$. The release experiments were conducted in triplicate under sink conditions, and average values with standard deviations were presented.

\section{In vitro cytotoxicity and antitumor efficacy}

The biocompatibility of blank micelles was evaluated using the CCK-8 assay. 293 T human embryonic kidney cells and $4 \mathrm{~T} 1$ breast cancer cells were separately seeded in 96-well plates $\left(6 \times 10^{3}\right.$ cells per well $)$ in 100 $\mu \mathrm{L}$ of culture medium and incubated for $24 \mathrm{~h}$.

Medium was removed and replaced with $100 \mu \mathrm{L}$ of medium containing different concentrations of blank micelles or DOX-loaded micelles. Then the cells were incubated for another $48 \mathrm{~h}$, the medium was removed, the wells were rinsed three times with PBS, and CCK-8 solution $(100 \mu \mathrm{L}$, volume fraction, $10 \%)$ was added to each well. The cells were incubated another $2 \mathrm{~h}$ in the dark, and absorbance was measured at $450 \mathrm{~nm}$ using a microplate reader (Thermo Scientific MK3, USA).

Antitumor activity of drug-loaded micelles against 4T1 cells was also evaluated using the CCK-8 assay. Cells were seeded and incubated for $24 \mathrm{~h}$ in 96-well plates as described above, then free DOX. $\mathrm{HCl}$ or DOXloaded micelles in culture medium were added at various DOX concentrations $(0.001-100 \mu \mathrm{g} / \mathrm{mL})$ and the cells were incubated another $48 \mathrm{~h}$. After that, the cells were subjected to the CCK- 8 assay as described above. confocal dishes $\left(2 \times 10^{4} \mathrm{~mL}^{-1}\right.$ cells per well $)$ and incubated for $24 \mathrm{~h}$. Then the medium was replaced with blank or DOX-loaded micelles $(10 \mu \mathrm{g} / \mathrm{mL}$ DOX) in culture medium and cells were incubated for 1 or $3 \mathrm{~h}$. The medium was removed and cells were washed three times with cold PBS, then examined using confocal laser scanning microscopy with excitation at $480 \mathrm{~nm}$ and emission at $590 \mathrm{~nm}$.

For the flow cytometry tests, 4T1 cells were seeded in 6 -well plates $\left(1 \times 10^{5} \mathrm{~mL}^{-1}\right.$ cells per well), incubated for $24 \mathrm{~h}$, then treated for 1 or $3 \mathrm{~h}$ with free DOX. $\mathrm{HCl}$ or DOX-loaded micelles $(10 \mu \mathrm{g} / \mathrm{mL}$ DOX). After that, medium was removed and cells were washed three times in PBS and harvested by trypsin treatment. Finally, cells were centrifuged (1000 rpm, $5 \mathrm{~min}$ ), resuspended in PBS, and analyzed using flow cytometry (BD FACSCanto II, USA).

\section{In vivo toxicity and antitumor efficacy}

All animal experiments were performed according to institutional guidelines and the recommendations of the US National Institutes of Health for the care and use of research animals. Male BALB/c mice $(18-20 \mathrm{~g})$ were purchased from West China Experimental Animal Culture Center of Sichuan University (Chengdu, China). 4T1 cells $\left(1 \times 10^{6}\right)$ were injected subcutaneously into the right flank, and when the inoculated tumors reached a volume of $100-200 \mathrm{~mm}^{3}$, the animals were randomized to receive one of the following treatments ( $n=8$ per group): saline, DOX $\cdot \mathrm{HCl}$, DOX/mPEG-ss-Tripp micelles, or DOX/ mPEG-Tripp micelles (DOX always at $5 \mathrm{mg} / \mathrm{kg}$ body). Treatments were delivered intravenously via the tail vein every 3 days for 4 treatments. Tumor volume and body weight were monitored at prescribed time intervals, and tumor volume was calculated using the formula: $\mathrm{V}$ $\left(\mathrm{mm}^{3}\right)=1 / 2 \times \mathrm{ab}^{2}$, where $\mathrm{a}$ and $\mathrm{b}$ are the largest and smallest diameters of the tumor, respectively.

At $21 \mathrm{~d}$ after the fourth treatment, all mice were sacrificed. Organs including heart, liver, spleen, lung, kidney and tumor were excised from each mouse and fixed in $4 \%$ formaldehyde. Representative tissues were paraffinembedded, sectioned, stained with hematoxylin and 
eosin and examined under a light microscope. Blood was assayed using standard serum tests performed by Chengdu Lilai Biotechnology (Chengdu, China) Tumor sections were immunostained with monoclonal antibody against Ki-67 to assess tumor proliferation, while sections were assayed by terminal deoxynucleotidyl transferasemediated deoxyuridine triphosphate nick-end labeling (TUNEL) to assess the level of apoptosis.

\section{Statistical analysis}

All data are presented as mean \pm standard deviation (SD). Inter-group differences were assessed for significance using Student's $t$ test, and $p<0.05$ was defined as significant.

\section{Results and discussion}

\section{Characterization of mPEG-ss-Tripp and mPEG-Tripp}

The conjugates mPEG-ss-Tripp and mPEG-Tripp were synthesized conveniently (Scheme 2), and the chemical structures of intermediates and final copolymers were confirmed by ${ }^{1} \mathrm{H}$ NMR. The protons of mPEGSAA showed chemical shifts at $\delta=3.35-3.40 \mathrm{ppm}(1)$, $\delta=3.50-3.80 \mathrm{ppm}(2,3)$ and $\delta=2.55-2.67 \mathrm{ppm}(4$, 5) (Fig. 1a). Conjugation with cystamine via an amido linkage gave peaks at $\delta=2.60-3.00 \mathrm{ppm}(7,8)$, which were assigned to the protons of $-\mathrm{CH}_{2} \mathrm{CH}_{2}$ in cystamine (Fig. 1b). The appearance of peaks at $\delta=7.70-7.80 \mathrm{ppm}$, attributed to an amide bond, confirmed that the cystamine segment was introduced into mPEG-SAA. The appearance of peaks at $\delta=6.50 \mathrm{ppm}$ (14) and $\delta=7.20$ $7.89 \mathrm{ppm}$ (9-13), attributed to the pyrrole and benzene rings, respectively (Fig. 1c), confirmed the synthesis of the amphiphilic polymer mPEG-ss-Tripp. In mPEGTripp, peaks at $\delta=3.35 \mathrm{ppm}$ (1) and $\delta=3.6 \mathrm{ppm}$ (2) were assigned, respectively, to protons in the terminal $\mathrm{CH}_{3}$ and $\mathrm{OCH}_{2} \mathrm{CH}_{2}$ in PEG. The other two peaks at $\delta=6.50 \mathrm{ppm}$ (6) and $\delta=7.08-7.73 \mathrm{ppm}(3,4,5,7,8)$ were attributed, respectively, to the pyrrole and benzene rings (Additional file 1: Figure S1).

\section{Preparation of blank and DOX-loaded micelles}

Based on dynamic light scattering, hydrodynamic diameters of blank micelles were $102 \mathrm{~nm}$ for mPEG-ss-Tripp and $99 \mathrm{~nm}$ for mPEG-Tripp (Fig. 2a), and loading the two micelles with DOX increased their respective diameters to 122 and $117 \mathrm{~nm}$ (Fig. 2b). With or without drug, micelles showed narrow size distributions, with a polydispersity index of $0.17-0.21$. Scanning electron microscopy showed uniform, spherical sizes that were consistent with the results of dynamic light scattering. These sizes can help nanoparticles to evade scavenging by mononuclear phagocytes as well as to target tumors passively through enhanced permeability and retention [33-35].
Micelles of mPEG-ss-Tripp and mPEG-Tripp showed respective DLCs of $10.5 \%$ and $10.1 \%$, and respective DLEs of $71.6 \%$ and $69.5 \%$. The relatively high DLC of micelles is due to the introduction of $\pi$-conjugated moieties (Tripp), which enhances $\pi-\pi$ stacking between DOX and amphiphilic polymers. After excitation at $485 \mathrm{~nm}$, free $\mathrm{DOX} \cdot \mathrm{HCl}$ emitted intense fluorescence from 500 to $700 \mathrm{~nm}$, while DOX/mPEG-ss-Tripp and DOX/mPEG-Tripp at the same DOX concentration $(25 \mu \mathrm{g} / \mathrm{mL}$ ) emitted much weaker signal (Additional file 1: Figure S2). This quenching is presumably due to the $\pi-\pi$ stacked DOX [36].

\section{AIE behavior of mPEG-ss-Tripp}

Since the Tripp-COOH groups, as the hydrophobic moieties in the amphiphile mPEG-ss-Tripp, are trapped inside the micellar cores during micelle formation, the aggregation state of Tripp-COOH molecules should trigger AIE. We confirmed this in vitro using a fluorescence assay. The mPEG-ss-Tripp dissolved in DMSO showed weak fluorescence, which increased dramatically when water was added to the DMSO solution (Fig. 3a). When the water fraction reached $99 \%(\mathrm{v} / \mathrm{v})$, fluorescence intensity of mPEG-ss-Tripp was nearly 74-fold stronger than in $100 \%$ DMSO (Fig. 3b). These results confirm the AIE of mPEG-ss-Tripp micelles.

\section{In vitro drug release}

Antitumor drug was expected to rapidly release as soon as drug-loaded micelles reached tumor tissue. The GSH triggered drug release of DOX-loaded micelles was investigated in PBS buffer solution at $\mathrm{pH} 7.4$ and $\mathrm{pH} 5.5$ with or without GSH (Fig. 3c). The amount of DOX released from mPEG-ss-Tripp micelles in the medium at $\mathrm{pH} 7.4$ contained $10 \mathrm{mM}$ GSH was less than $45 \%$ after $72 \mathrm{~h}$, while more than $70 \%$ was released in acidic medium at pH 5.5 in the absence of GSH. Remarkably, drug release was quicker in acidic medium in the presence of $10 \mathrm{mM}$ GSH, with more than $96 \%$ of drug release after $72 \mathrm{~h}$. These results suggest that, as desired, our nanosystem delivers drug cargo selectively within cells, in response to the microenvironment of tumor and enhanced antitumor efficacy.

\section{Change in micelle size in response to GSH}

Dynamic light scattering showed that mPEG-ss-Tripp micelles swelled rapidly in the presence of GSH: in the presence of $0.5 \mathrm{mM} \mathrm{GSH}$, average size increased from 105 to $342 \mathrm{~nm}$ within $5 \mathrm{~h}$; in the presence of $10 \mathrm{mM}$ GSH, average size increased from 342 to $531 \mathrm{~nm}$ in $5 \mathrm{~h}$, and to $>1600 \mathrm{~nm}$ in $12 \mathrm{~h}$ (Fig. 4a). In contrast, the size of mPEG-Tripp micelles changed little even after $12 \mathrm{~h}$ in the presence of $10 \mathrm{mM} \mathrm{GSH}$. Consistent with GSH-triggered 
(I) Synthesis of mPEG-ss-Tripp

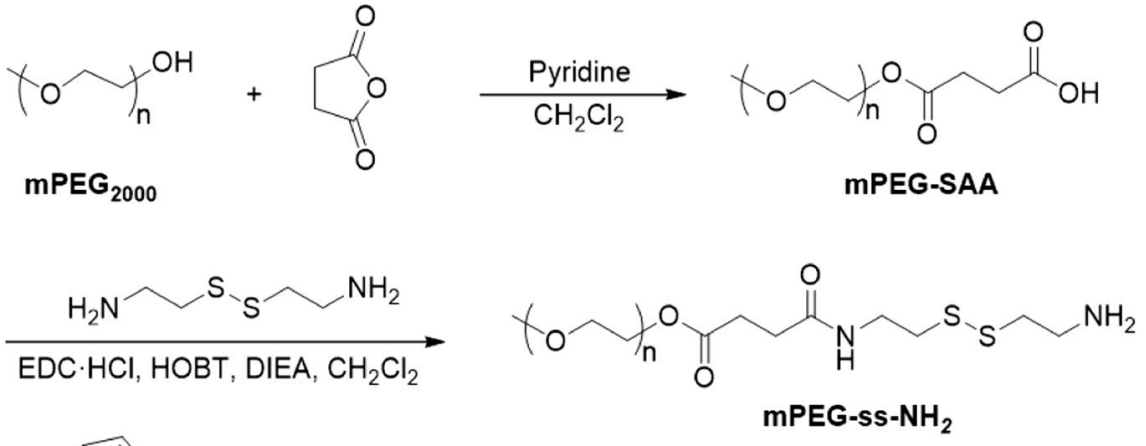<smiles>CC(C)(C)OCCC(=O)OCCC(=O)NCCSSCCNC(=O)c1ccc(-n2c(-c3ccccc3)ccc2-c2ccccc2)cc1</smiles>

(II) Synthesis of mPEG-Tripp

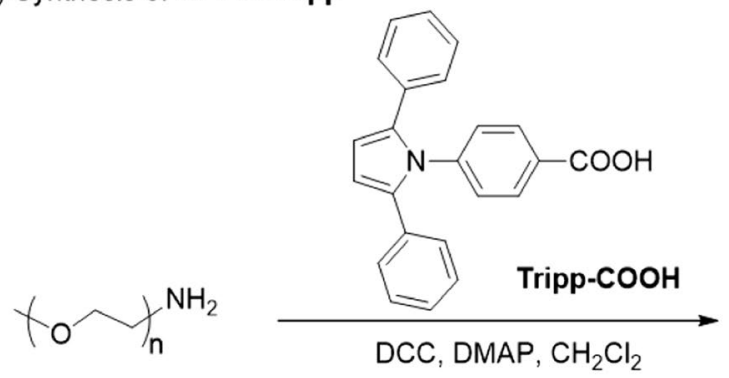<smiles>CC(C)(C)OCCNC(=O)c1ccc(-n2c(-c3ccccc3)ccc2-c2ccccc2)cc1</smiles>

Scheme 2 Synthesis of the mPEG-ss-Tripp (I) and mPEG-Tripp (II) copolymer

micelle opening and drug release, the count rate of the mPEG-ss-Tripp micelles decreased with time and with increasing GSH concentration (Fig. 4b). These results suggest that $10 \mathrm{mM}$ GSH can trigger complete dissolution of mPEG-ss-Tripp micelles.

\section{In vitro cytotoxicity of micelles}

$293 \mathrm{~T}$ and 4T1 cells were utilized to evaluate the potential cytotoxicity of blank micelle and DOX-loaded micelles based on the CCK-8 assay (Fig. 5a and b). Both cells showed great cell viability after $48 \mathrm{~h}$ incubation even the concentration of blank micelles increased to $200 \mu \mathrm{g} / \mathrm{mL}$. In addition, DOX-loaded micelles also exhibited negligible toxicity against $293 \mathrm{~T}$ cell. However, great cell toxicity of 4T1 cells treated with DOX-loaded micelles was observed, and DOX/mPEG-Tripp micelles showed lower inhibition efficiency than that of DOX/mPEG-ss-Tripp micelles. Therefore, the difference in potency between cancer cell lines and normal cell lines indicated good tumor selectivity of DOX/mPEG-ss-Tripp micelles. At the same time, DOXloaded micelles reduced the viability of $4 \mathrm{~T} 1$ cells, although their half-maximal inhibitory concentrations $\left(\mathrm{IC}_{50}\right)$ were 
a

$$
1 \text { ro } \overbrace{3^{n}}^{2} \prod_{0}^{4} \overbrace{5}^{0}
$$

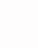

b
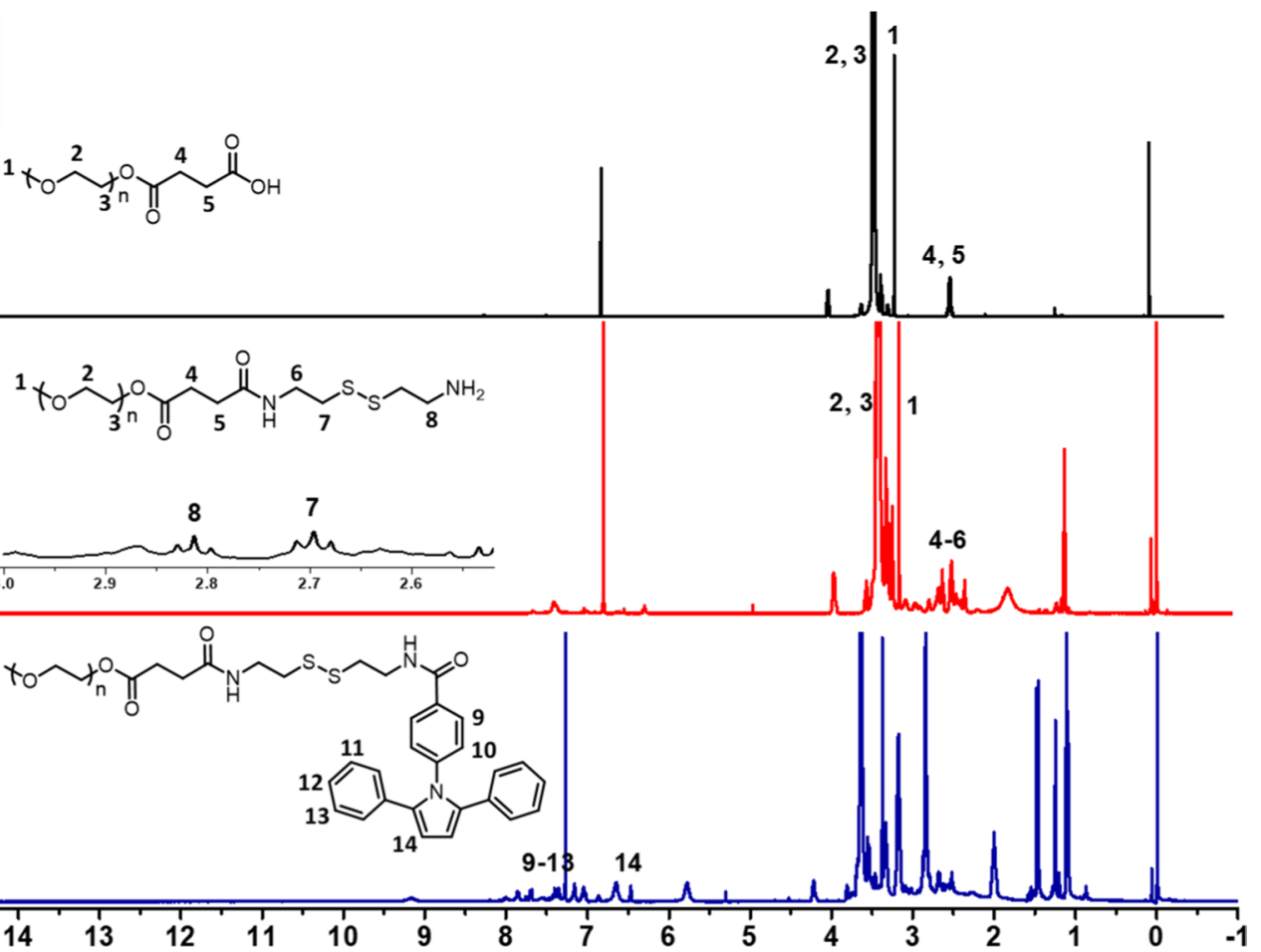

Fig. 1. ${ }^{1} \mathrm{H}$ NMR spectra of mPEG-SAA $\left(\mathrm{CDCl}_{3}\right)(\mathbf{a})$; mPEG-SS-NH ${ }_{2}\left(\mathrm{DMSO}-d_{6}\right)(\mathbf{b})$ and $\mathrm{mPEG}-\mathrm{ss}-$ Tripp $\left(\mathrm{DMSO}-d_{6}\right)(\mathbf{c})$
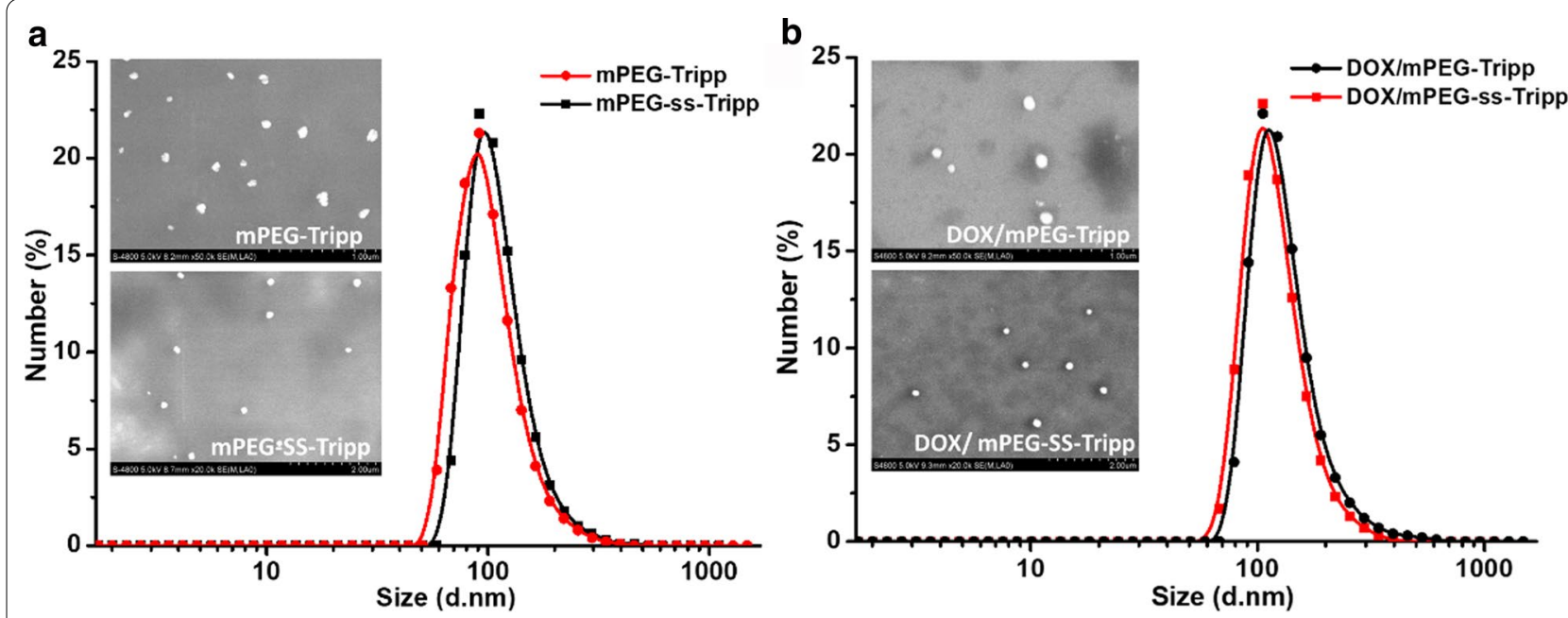

Fig. 2 DLS and SEM images of blank micelles (a); DOX-loaded micelles (b) 
higher than for free DOX (mPEG-ss-Tripp, $1.65 \mu \mathrm{g} /$ $\mathrm{mL}$; mPEG-Tripp, $12.74 \mu \mathrm{g} / \mathrm{mL}$; free DOX.HCl, $0.71 \mu \mathrm{g} /$ $\mathrm{mL}$ (Fig. $5 \mathrm{c}$ and d). The greater anticancer activity of free DOX likely reflects its ability to enter cells by passive diffusion. The much greater anticancer activity of mPEG-ssTripp than mPEG-Tripp likely reflects that cleavage of the disulfide bond within cells triggers faster drug release from the micelle interior than simple diffusion.

\section{Intracellular imaging of AIE micelles in vitro}

Uptake of micelles and intracellular release of drug were analyzed using confocal fluorescence microscopy and flow cytometry on the basis of AIE signal. Within $1 \mathrm{~h}$ of incubation with blank or DOX-loaded micelles, blue
AIE fluorescence was clearly visible within the cytoplasm of $4 \mathrm{~T} 1$ cells (Fig. 6a), suggesting rapid internalization of micelles via endocytosis. Cells incubated with free DOX. $\mathrm{HCl}$ showed red fluorescence mainly in nuclei, reflecting the excellent aqueous solubility of DOX and its ability to enter cells and nuclei by passive diffusion. However, for the DOX-loaded micelles, most red fluorescence of DOX was concentrated in cytoplasm; only weak red fluorescence was observed in nuclei. Both red and blue fluorescence intensity were higher at $3 \mathrm{~h}$ than at $1 \mathrm{~h}$, confirming that more drug-loaded micelles were internalized into cells and sustainably released the drug intracellularly. These experiments confirm that DOX-loaded micelles can be used for bioimaging and drug delivery.
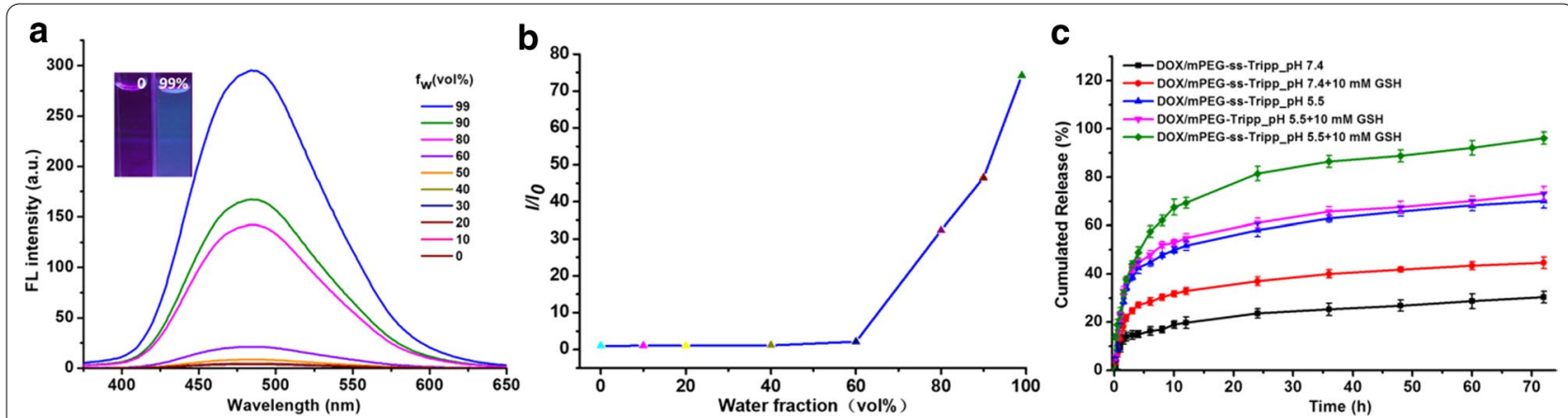

Fig. 3 The fluorescent spectra of mPEG-ss-Tripp in DMSO/water mixtures with different fractions of water $\left(f_{w}\right)$, insert image showing fluorescence of mPEG-ss-Tripp solutions dissolved in pure DMSO and 99\% water (a); plot of fluorescent intensity of mPEG-ss-Tripp versus water content of DMSO/ water mixture, $\mathrm{I}=$ fluorescent intensity of $\mathrm{mPEG}$-ss-Tripp in mixed solution, $\mathrm{I}_{0}=$ fluorescent intensity of mPEG-ss-Tripp in pure DMSO $(\lambda$ ex $=330 \mathrm{~nm})$ (b); the release profiles of DOX-loaded micelles triggered with or without GSH at pH 7.4 and pH 5.5, means \pm SD $(n=3)(\mathbf{c})$
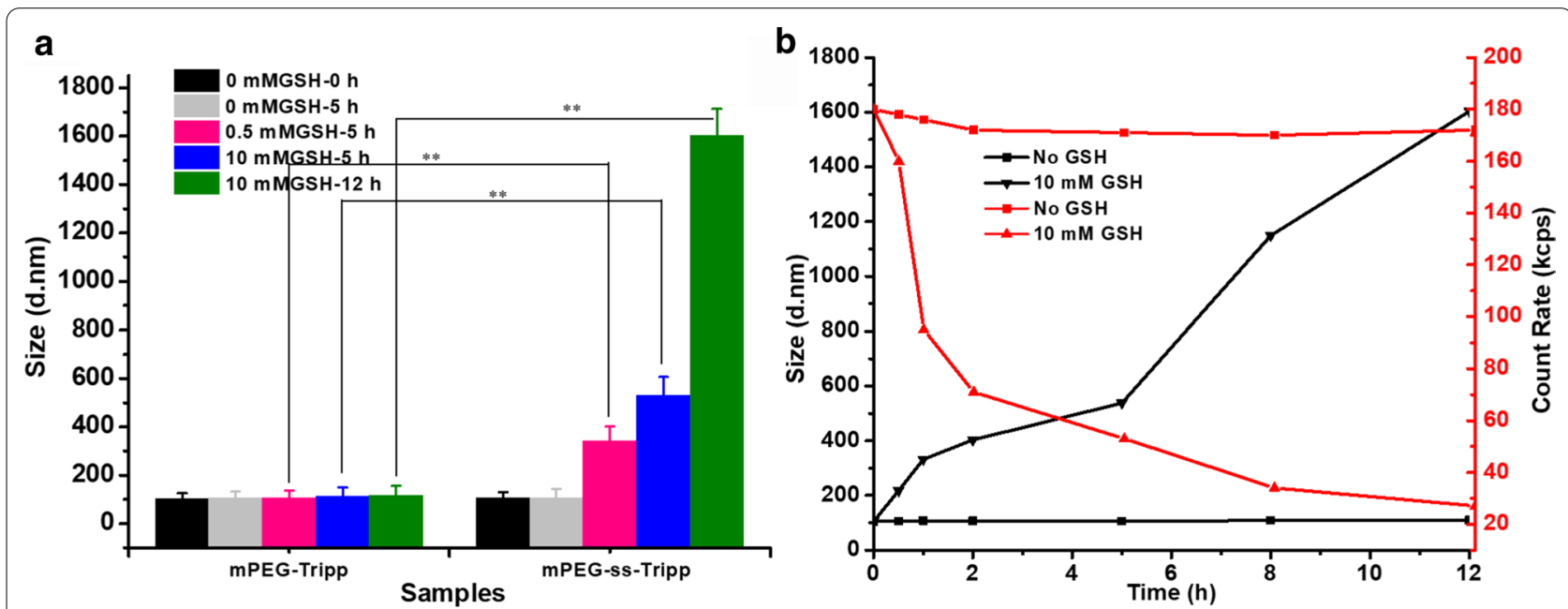

Fig. 4 The size changes of mPEG-Tripp and mPEG-ss-Tripp micells in different concentration of GSH solution (a); the size changes and the count rate of mPEG-ss-Tripp micells over time with or without $10 \mathrm{mM} \mathrm{GSH}(\mathbf{b}),{ }^{* *} \mathrm{P}<0.01$ 
The results of confocal microscopy were confirmed using flow cytometry. While control cells showed only autofluorescence, cells treated with DOX. $\mathrm{HCl}$ showed the strongest fluorescence, followed by cells treated with mPEG-ss-Tripp and finally cells treated with mPEGTripp (Fig. 7a and b).

\section{In vivo toxicity and antitumor efficacy of micelles}

Tumor-bearing BALB/c mice were treated every 3 days with saline, DOX.HCl or DOX-loaded micelles. By 21 days of treatment, the tumor volume in the saline group had increased rapidly (Fig. 8a), indicating that the saline did not have any therapeutic effect. DOX. $\mathrm{HCl}$ and DOX-loaded micelles, in contrast, strongly inhibited tumor growth. Notably, treatment with mPEGss-Tripp group showed better anticancer activity than mPEG -Tripp group. In addition, the picture of harvested tumors and the average tumor weight of each group further confirmed the greater antitumor efficacy of mPEGss-Tripp micelles (Additional file 1: Figure S3A and B). Over the same period, the DOX induced toxicity was reflected by body weight change of mice (Fig. 8b). There was no body weight loss for saline treated mice. However, a severe body weight loss could be observed for the
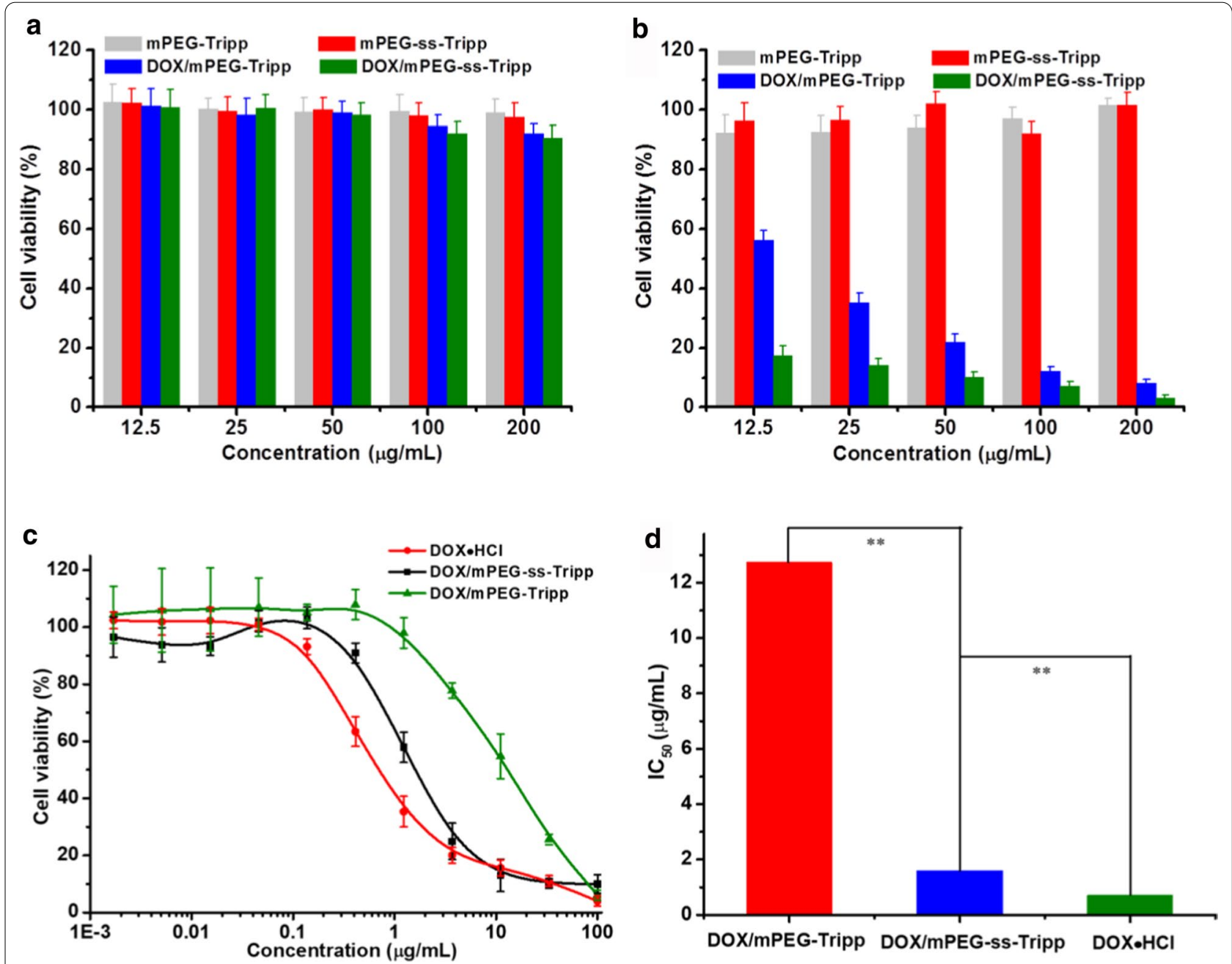

Fig. 5 In vitro cell viability and antitumor efficiency. Cell viability versus concentrations of various blank micelles and DOX-loaded micelles against the normal cell line $293 \mathrm{~T}$ (a) and the tumor cell line 4T1 (b); Cell viability of 4T1 cells versus concentrations of various formulations with incubation for $48 \mathrm{~h}$ (means $\pm S D, n=3)(\mathbf{c}) ; I C_{50}$ values of various formulations to $4 T 1$ cells $(\mathbf{d}),{ }^{* *} P<0.01$ 
free DOX treated mice. On the contrary, the body weight changes of mice did not show distinct difference in DOXloaded micelles treatment group and the control group, indicating a significant lower toxicity than free DOX. Consistent with this idea, all mice treated with DOXloaded micelles survived for the entire period of 33 days, whereas $40 \%$ of mice treated with free $\mathrm{DOX} \cdot \mathrm{HCl}$ died within 18 days (Fig. 8c). Therefore, it could be confirmed that DOX-loaded micelles would be a good candidate for tumor therapy with an improved antitumor efficacy and decreased side effects.

Serum biochemistry assays confirmed that free $\mathrm{DOX} \cdot \mathrm{HCl}$ was strongly toxic, which was reflected in elevated aspartate transaminase (AST), alanine aminotransferase (ALT) and alkaline phosphatase (ALP) (Fig. 8d). Indices in animals treated with DOX-loaded micelles were close to those in the saline group, indicating that the DOX-loaded micelles did not obviously harm tumor-bearing mice.

Hematoxylin-eosin staining of tumor tissue showed nearly no apoptosis or necrosis in the saline group, while it showed tumor necrosis with hemorrhage in the groups treated with free DOX.HCl or DOX-loaded micelles (Fig. 9). Staining of slices indicated that obvious cardiotoxicity could be observed in mice treated with free DOX, whereas no obvious abnormity was observed for
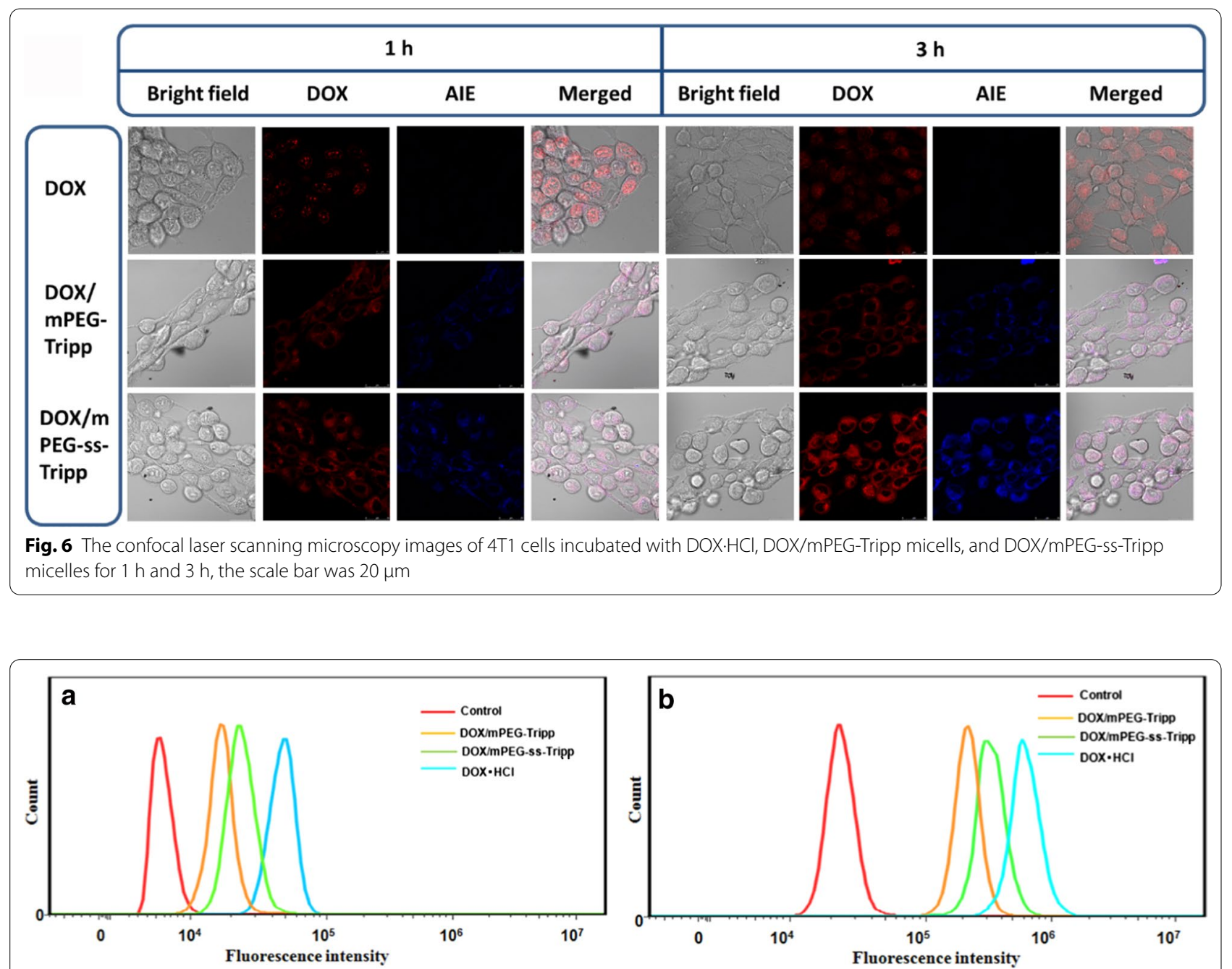

Fig. 7 The flow cytometry histogram profiles of $4 \mathrm{~T} 1$ cells incubated with DOX.HCl, DOX/mPEG-Tripp micells and DOX/mPEG-ss-Tripp micelles for $1 \mathrm{~h}(\mathbf{a})$ and $3 \mathrm{~h} \mathrm{(b)}$, the DOX concentration was $10 \mu \mathrm{g} / \mathrm{mL}$ 


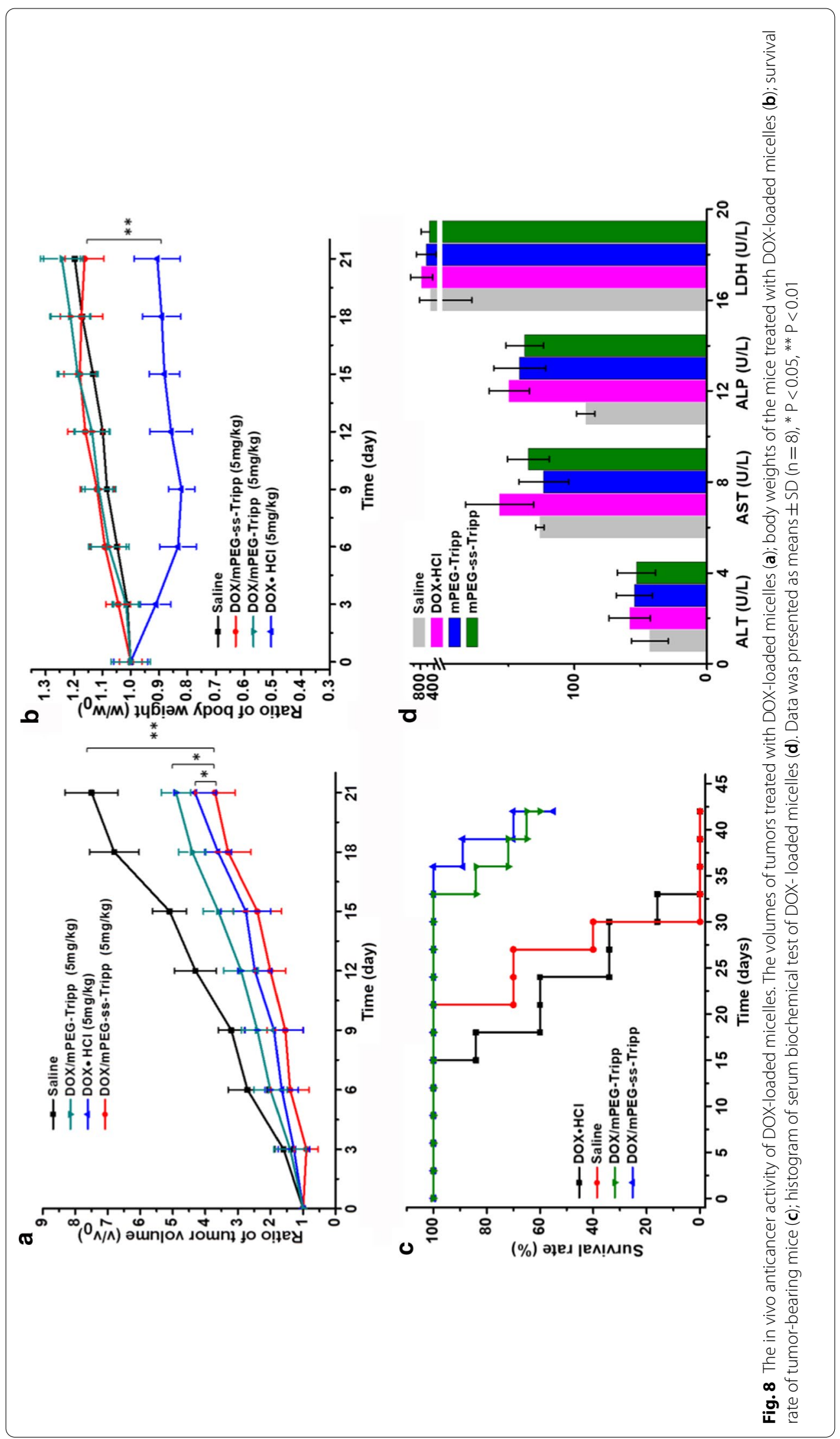




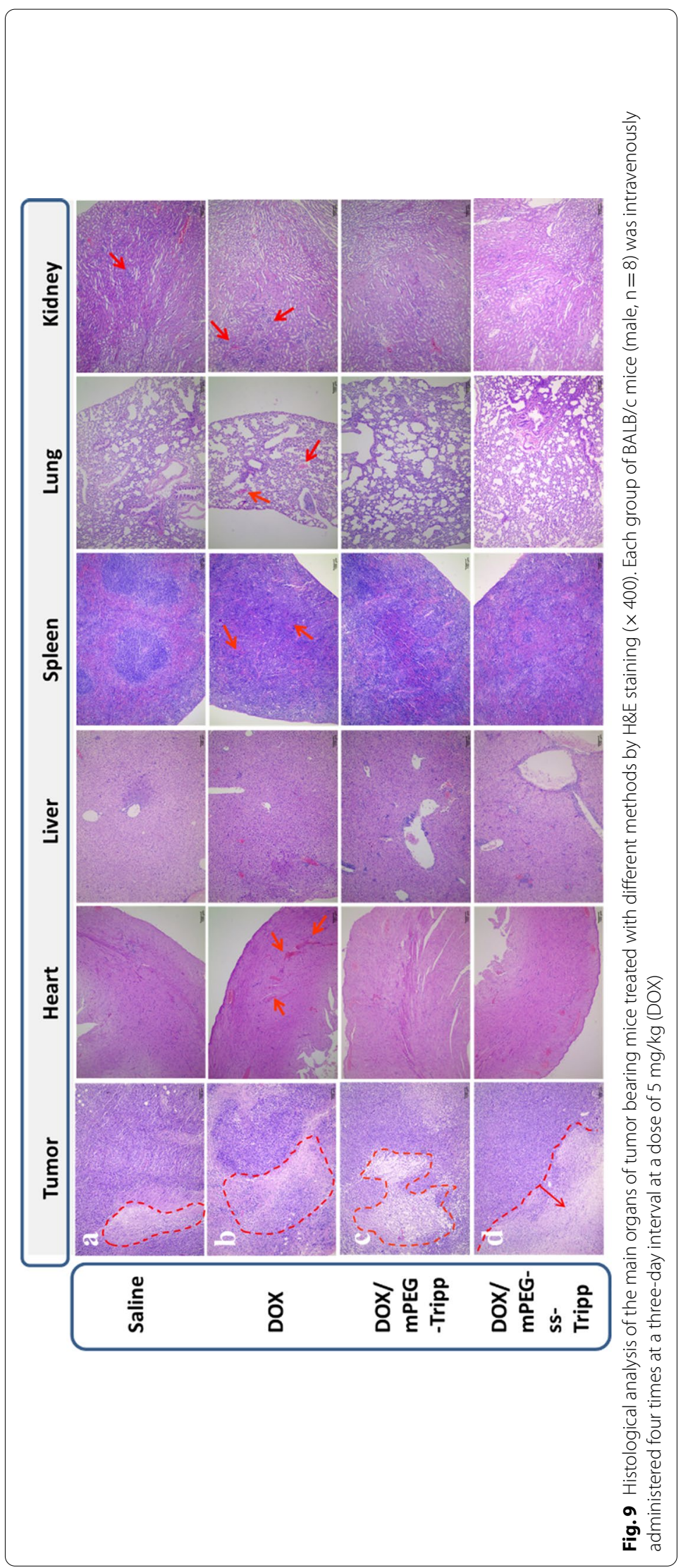




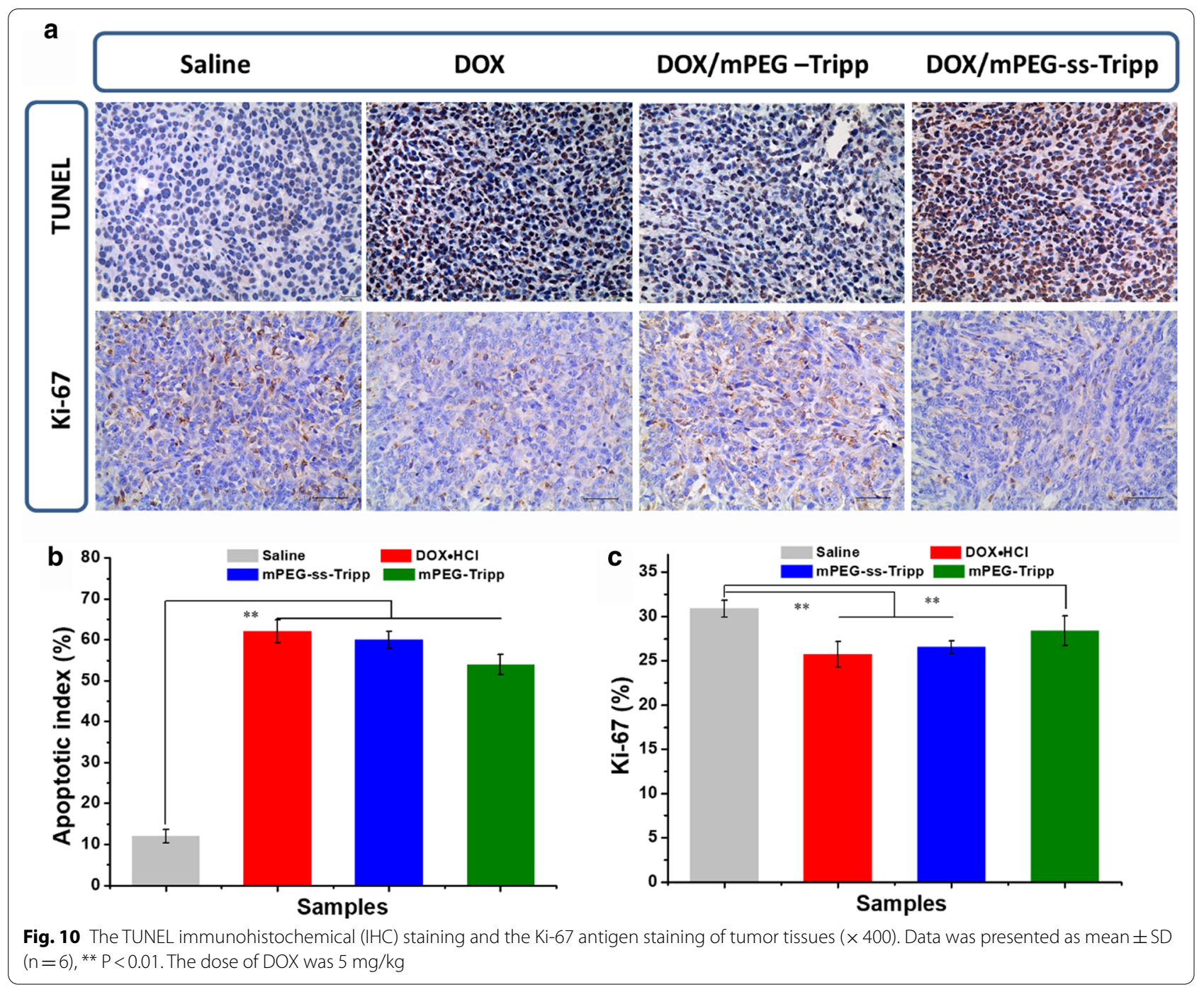

the cardiac tissue treated with DOX-loaded micelles. Meanwhile, compared with DOX-loaded micelles, free DOX exhibited more focal necrosis and inflammation in lungs, spleen, and kidney, such as lobular pneumonia in lungs, white pulp atrophy and splenic corpuscle disappearance in spleen, swelling and shrinkage or disappearance of kidney glomerular cells.

\section{Immunohistochemistry and TUNEL staining}

Tissue sections stained against Ki-67 antigen as an index of tumor proliferation showed that mPEG-ss-Tripp micelles suppressed proliferation more than other treatments (Fig. 10). These results confirm that the redox-sensitive of the drug delivery system can improve therapeutic efficacy in vivo.

These in vivo experiments indicate that mPEG-ss-Tripp micelles lead to substantially lower toxicity than free
$\mathrm{DOX} \cdot \mathrm{HCl}$ and greater efficacy than redox-insensitive mPEG-Tripp micelles.

\section{Conclusions}

We have designed a novel redox-sensitive amphiphilic polymer with AIE character to realize a drug delivery system for simultaneous cellular imaging and cancer therapy. When loaded with DOX, the amphiphilic polymer can self-assemble into drug-loaded micelles, which release their therapeutic cargo rapidly in response to reduction of the disulfide linkage at the high GSH concentrations inside cells. The micelles can be tracked within cells by virtue of their AIE. Removing the redoxsensitive disulfide bridge makes drug delivery slower and less effective against tumors. These results open up new possibilities for multifunctional drug delivery systems. 


\section{Supplementary Information}

The online version contains supplementary material available at https://doi. org/10.1186/s12951-020-00761-9.

Additional file 1: Figure S1. ${ }^{1} \mathrm{H}$ NMR spectra of mPEG-Tripp. Figure S2. Fluorescence spectra of micelles in aqueous solution at $485 \mathrm{~nm}$ excitation wavelength. Figure S3. Image of tumors after treatment for three weeks with different formulations after 21 days.

\section{Acknowledgements}

Not applicable.

\section{Authors' contributions}

All authors contributed significantly to this work. BH, ZZ, and NH conceived and designed the experiments. CS and $J L$ performed the experiments. CS, JL, $J W, P H, C L, L Q, L Y$ analyzed the data. NH, BH and ZZ oversaw the design of the experiments, data analysis, and edited the manuscript. CS and JL contributed equally in this work. All authors read and approved the final manuscript.

\section{Funding}

The authors thank for the support of the collaborative fund of Luzhou Government and Southwest Medical University (2019LZXNYDJ16), the Transformation Project of Science and Technology Achievements of Southwest Medical University (2018002) and the research fund of Southwest Medical University (2017-ZRQN-037, 2019ZZD004).

\section{Availability of data and materials}

All data generated or analyzed during this study are included in this published article and its Additional file 1.

\section{Ethics approval and consent to participate}

All of the animal experiments were carried out in accordance with the guidelines issued by Southwest Medical University and were approved by the Ethical Committee of Southwest Medical University.

\section{Content for publication}

All authors agreed to submit this manuscript.

\section{Competing interests}

The authors declare that they have no competing interests.

\section{Author details \\ ${ }^{1}$ Department of Pharmaceutical Sciences, School of Pharmacy, Southwest Medical University, Luzhou 646000, China. ${ }^{2}$ Affiliated Traditional Chinese Med- icine Hospital, Southwest Medical University, Luzhou 646000, China. ${ }^{3}$ Biologi- cal group, Beijing Huimin School, Beijing 100032, China. ${ }^{4}$ National Engineer- ing Research Center for Biomaterials, Sichuan University, Chengdu 610064, China.}

Received: 29 August 2020 Accepted: 19 December 2020

Published online: 07 January 2021

\section{References}

1. Hettiarachchi SD, Graham RM, Mintz KJ, Zhou Y, Vanni S, Peng Z, Leblanc RM. Triple conjugated carbon dots as a nano-drug delivery model for glioblastoma brain tumors. Nanoscale. 2019;11:6192-205.

2. Xu L, Zhao M, Gao W, Yang Y, Zhang J, Pu Y, He B. Polymeric nanoparticles responsive to intracellular ROS for anticancer drug delivery. Colloid Surf B-Biointerfaces. 2019;181:252-60.

3. Sun HL, Guo BN, Cheng R, Meng FH, Liu HY, Zhong ZY. Biodegradable micelles with sheddable poly(ethylene glycol) shells for triggered intracellular release of doxorubicin. Biomaterials. 2009;30:6358-66.

4. Liu CY, Yuan J, Luo XM, Chen MH, Chen ZJ, Zhao YC, Li XH. Folatedecorated and reduction-sensitive micelles assembled from amphiphilic polymer-camptothecin conjugates for intracellular drug delivery. $\mathrm{Mol}$ Pharmaceutics. 2014:11:4258-69.
5. Wang H, Liu G, Dong S, Xiong J, Du Z, Cheng X. A pH-responsive AlE nanoprobe as a drug delivery system for bioimaging and cancer therapy. J Mat Chem B. 2015:3:7401-7.

6. Xue X, Zhao Y, Dai L, Zhang X, Hao X, Zhang C, Huo S, Liu J, Liu C, Kumar A, Chen W-Q, Zou G, Liang X-J. Spatiotemporal drug release visualized through a drug delivery system with tunable aggregation-induced emission. Adv Mater. 2014:26:712-7.

7. Mura S, Nicolas J, Couvreur P. Stimuli-responsive nanocarriers for drug delivery. Nat Mater. 2013;12:991-1003.

8. Zhang C, Jin S, Li S, Xue X, Liu J, Huang Y, Jiang Y, Chen W-Q, Zou G, Liang $X$-J. imaging intracellular anticancer drug delivery by self-assembly micelles with aggregation-induced emission (AIE Micelles). ACS Appl Mater Interfaces. 2014;6:5212-20.

9. Zhang L, Wang T, Yang L, Liu C, Wang C, Liu H, Wang YA, Su Z. General route to multifunctional uniform yolk/mesoporous silica shell nanocapsules: a platform for simultaneous cancer-targeted imaging and magnetically guided drug delivery. Chem-Eur J. 2012;18:12512-21.

10. Chen Y-F, Hong J, Wu D-Y, Zhou Y-Y, D'Ortenzio M, Ding Y, Xia X-H. In vivo mapping and assay of matrix metalloproteases for liver tumor diagnosis. RSC Adv. 2016;6:8336-45.

11. Ma J, Wu L, Hou Z, Song Y, Wang L, Jiang W. Visualizing the endocytosis of phenylephrine in living cells by quantum dot-based tracking. Biomaterials. 2014;35:7042-9.

12. Peng T, Chen X, Gao L, Zhang T, Wang W, Shen J, Yang D. A rationally designed rhodamine-based fluorescent probe for molecular imaging of peroxynitrite in live cells and tissues. Chem Sci. 2016;7:5407-13.

13. Reisch A, Klymchenko AS. Fluorescent polymer nanoparticles based on dyes: seeking brighter tools for bioimaging. Small. 2016;12:1968-92.

14. Yuan Y, Kwok RTK, Tang BZ, Liu B. Targeted Theranostic platinum(IV) prodrug with a built-in aggregation-induced emission light-up apoptosis sensor for noninvasive early evaluation of its therapeutic responses in situ. J Am Chem Soc. 2014;136:2546-54.

15. Zrazhevskiy P, Sena M, Gao X. Designing multifunctional quantum dots for bioimaging, detection, and drug delivery. Chem Soc Rev. 2010;39:4326-54

16. Ding D, Li K, Liu B, Tang BZ. Bioprobes based on AlE fluorogens. Accounts Chem Res. 2013;46:2441-53.

17. Luo J, Xie Z, Lam JWY, Cheng L, Chen H, Qiu C, Kwok HS, Zhan X, Liu Y, Zhu D, Tang BZ. Aggregation-induced emission of 1-methyl-1,2,3,4,5pentaphenylsilole. Chem Commun. 2001;18:1740-1.

18. Shi H, Kwok RTK, Liu J, Xing B, Tang BZ, Liu B. Real-time monitoring of cell apoptosis and drug screening using fluorescent light-up probe with aggregation-induced emission characteristics. J Am Chem Soc. 2012;134:17972-81.

19. Singh VD, Singh RS, Paitandi RP, Dwivedi BK, Maiti B, Pandey DS. Solventdependent self-assembly and aggregation-induced emission in Zn(II) complexes containing phenothiazine-based terpyridine ligand and its efficacy in pyrophosphate sensing. J Phys Chem C. 2018;122:5178-87.

20. Su X, Ma B, Hu J, Yu T, Zhuang W, Yang L, Li G, Wang Y. Dual-responsive doxorubicin-conjugated polymeric micelles with aggregation-induced emission active bioimaging and charge conversion for cancer therapy. Bioconjugate Chem. 2018;29:4050-61.

21. Zhang R, Sung SHP, Feng G, Zhang C-J, Tang BZ, Liu B. Aggregationinduced emission probe for specific turn-on quantification of soluble transferrin receptor: an important disease marker for iron deficiency anemia and kidney diseases. Anal Chem. 2018;90:1154-2116.

22. Guo X, Shi C, Wang J, Di S, Zhou S. pH-triggered intracellular release from actively targeting polymer micelles. Biomaterials. 2013;34:4544-54.

23. Hu H, Li Y, Zhou Q, Ao Y, Yu C, Wan Y, Xu H, Li Z, Yang X. Redox-sensitive hydroxyethyl starch-doxorubicin conjugate for tumor targeted drug delivery. ACS Appl Mater Interfaces. 2016;8:30833-44.

24. Lee S-Y, Kim S, Tyler JY, Park K, Cheng J-X. Blood-stable, tumor-adaptable disulfide bonded mPEG-(Cys)4-PDLLA micelles for chemotherapy. Biomaterials. 2013:34:552-61.

25. Luan S, Zhu Y, Wu X, Wang Y, Liang F, Song S. Hyaluronic-acid-based $\mathrm{pH}$-sensitive nanogels for tumor-targeted drug delivery. ACS Biomater Sci Eng. 2017;3:2410-9.

26. Xu L, Zhao M, Zhang H, Gao W, Guo Z, Zhang X, Zhang J, Cao J, Pu Y, He B. Cinnamaldehyde-based Poly(ester-thioacetal) to generate reactive oxygen species for fabricating reactive oxygen species-responsive nanoparticles. Biomacromol. 2018;19:4658-67. 
27. Dai L, Li J, Zhang B, Liu J, Luo Z, Cai K. Redox-Responsive nanocarrie based on heparin end-capped mesoporous silica nanoparticles for targeted tumor therapy in vitro and in vivo. Langmuir. 2014;30:7867-77.

28. Yi Q, Ma J, Kang K, Gu Z. Dual cellular stimuli-responsive hydrogel nanocapsules for delivery of anticancer drugs. J Mat Chem B. 2016;4:4922-33.

29. Liu Z, Shen N, Tang Z, Zhang D, Ma L, Yang C, Chen X. An eximious and affordable GSH stimulus-responsive poly(a-lipoic acid) nanocarrier bonding combretastatin A4 for tumor therapy. Biomater Sci. 2019;7:2803-11.

30. Zhang T-T, Xu C-H, Zhao W, Gu Y, Li X-L, Xu J-J, Chen H-Y. A redoxactivated theranostic nanoagent: toward multi-mode imaging guided chemo-photothermal therapy. Chem Sci. 2018;9:6749-57.

31. Shuai X, Ai H, Nasongkla N, Kim S, Gao J. Micellar carriers based on block copolymers of poly( $\varepsilon$-caprolactone) and poly(ethylene glycol) for doxorubicin delivery. J Control Release. 2004;98:415-26.

32. Hao N, Sun C, Wu Z, Xu L, Gao W, Cao J, Li L, He B. Fabrication of polymeric micelles with aggregation-induced emission and forster resonance energy transfer for anticancer drug delivery. Bioconjugate Chem. 2017;28:1944-54.

33. Jiang Y, Lu H, Khine YY, Dag A, Stenzel MH. Polyion complex micelle based on albumin-polymer conjugates: multifunctional oligonucleotide transfection vectors for anticancer chemotherapeutics. Biomacromol. 2014;15:4195-205.
34. Maeda H, Wu J, Sawa T, Matsumura Y, Hori K. Tumor vascular permeability and the EPR effect in macromolecular therapeutics: a review. J Control Release. 2000;65:271-84.

35. Wang H, He J, Cao D, Zhang M, Li F, Tam KC, Ni P. Synthesis of an acidlabile polymeric prodrug DOX-acetal-PEG-acetal-DOX with high drug loading content for $\mathrm{pH}$-triggered intracellular drug release. Polym Chem. 2015;6:4809-18.

36. Liang Y, Deng X, Zhang L, Peng X, Gao W, Cao J, Gu Z, He B. Terminal modification of polymeric micelles with $\pi$-conjugated moieties for efficient anticancer drug delivery. Biomaterials. 2015;71:1-10.

\section{Publisher's Note}

Springer Nature remains neutral with regard to jurisdictional claims in published maps and institutional affiliations. 